\title{
EVALUATION OF COLOUR CHANGES, SURVIVAL RATE AND LIFE SPAN OF THE CONFUSED SAP BEETLE (Carpophilus mutilatus) (COLEOPTERA: NITIDULIDAE) IN DIFFERENT CONCENTRATIONS OF CARBON DIOXIDE $\left(\mathrm{CO}_{2}\right)$
}

\author{
NOR-ATIKAH, A. R. - HALIM, M. - NUR-HASYIMAH, H. - YAAKOP, S. ${ }^{*}$ \\ Centre for Insect Systematics, Department of Biological Sciences and Biotechnology, Faculty of \\ Science and Technology, Universiti Kebangsaan Malaysia (UKM), 43600 Bangi, Selangor, \\ Malaysia \\ ${ }^{*}$ Corresponding author \\ e-mail:salmah78@ukm.edu.my; phone: +60-389-215-698
}

(Received $8^{\text {th }}$ Apr 2020; accepted $13^{\text {th }}$ Aug 2020)

\begin{abstract}
This study conducted in a rearing room (RR) (300-410 ppm) and in an open roof ventilation greenhouse system (ORVS) (800-950 ppm). No changes observed on Carpophilus mutilatus colouration after treatment in the ORVS. The survival rate increased from $61.59 \%$ in the F1 to $73.05 \%$ in the F2 generation reared in the RR. However, a sharp decline was observed from $27.05 \%$ in F1 to $1.5 \%$ in F2 in the ORVS. There was significant difference in number of individuals between RR and ORVS in F1 and F2 $(\mathrm{F} 12.76 \mathrm{p}=0.001<0.05)$. The life span of $\mathrm{F} 1$ and $\mathrm{F} 2$ in the RR took about 46 days to complete; $7-21$ days from adult to larvae stage, 5-15 days from the larval to pupal stage and 3-10 days from adult to pupal stage. Whereas in ORVS, F1 and F2 took about 30 and 22 days, respectively to complete their life cycles; that is 7-14, 7-14 days (adult to larval stage), 5-10, 0-5 days (larval to pupal stage) and 3-6, 0-3 days (pupal to adult stage), respectively. These data can be used to describe the changes in C. mutilatus due to global warming effects, as $\mathrm{CO}_{2}$ could be one of the main factors affecting the growth and development.
\end{abstract}

Keywords: morphology, biology, climate change, insects, global warming

\section{Introduction}

The life cycle and life span of insects depend on a variety of factors including biotic and abiotic factors. Biological information regarding the life cycle, life span and mortality rates of important groups of insects, especially pests and natural enemies, are crucially important for the biological control program (Gurr et al., 2000; Khaliq et al., 2014). These parameters are usually studied under laboratory conditions where the insects are reared in cages closely representing their native habitat, with the advantage that the studied parameters and test animals are well controlled and the trials can be carried out more easily than in the field (Leppla, 2009). Insect rearing in the laboratory is important as the basis for developing a cost-effective large-scale mass-rearing in Integrated Pest Management (IPM) (Echegaray and Cloyd, 2013). Nitidulid beetles in the genus Carpophilus are important pests of dried fruit worldwide but have recently also become serious pests of ripening stone fruit in southern Australia (James and Vogele, 2000), as well as palms, including dates and oil palm fruits (Blumberg, 2008; Nor Atikah et al., 2019). Adult beetles damage fruit either by chewing through the skin, usually at the stem end, or entering from the sites of mechanical damage.

Taxonomists also implemented a rearing method as the first step for species identification, especially at the early stage. The insect larvae and pupae need to be reared into adult stage in order to identify the species correctly (Gibbs et al., 2015). However, insect rearing methods often require optimum conditions that correlate with their natural 
habitats so that the insects are healthy, free from disease and can reproduce for future generations. Therefore, factors such as environmental conditions, food sources and rearing chambers should be appropriate, simple and cost-effective (Cohen, 2018). The rearing of nitidulid beetles in the laboratory had been studied to determine their diets (Dowd, 1987; Peng and Williams, 1990; Dowd and Weber, 1991) and under different temperature conditions (De Guzman and Frake, 2007; Cuthbertson et al., 2008) to measure their survival, development and reproduction rates (Tsukada et al., 2005; Okada and Miyatake, 2007; Meikle and Patt, 2011).

Greenhouse gases such as carbon dioxide, ethane and nitrous oxide are often associated with global warming (Cox et al., 2000; Root et al., 2003; Ainsworth and Long, 2005; Meinshausen et al., 2009). $\mathrm{CO}_{2}$ accounts for about $82 \%$ of greenhouse gas emissions compared to other gases (EPA's Greenhouse Gas Inventory 2017). The $\mathrm{CO}_{2}$ gas that is trapped in the atmosphere captures heat and prevents it from being released, which can lead to global warming. This phenomenon affects biological changes in many organisms such as animals and plants (Hunter, 2001; Peñuelas et al., 2002; Mondor and Tremblay, 2010; DeLucia et al., 2012; Khaliq et al., 2014). Insects are expected to be more vulnerable and sensitive to environmental changes as they are ectothermic organisms and have a short lifespan (Bale et al., 2002). For example, long-term studies on Lepidoptera found that the life cycles of this insect group are shorter as a result of global temperature changes (Roy and Sparks, 2000; Peñuelas et al., 2002; Wallis de Vries and van Swaay, 2006). The distribution of the lepidopteran species from the family Geometridae was elevated by 67 meters of altitude over 42 years due to increasing annual temperatures (Chen et al., 2009).

Previous studies, mostly conducted between 1980-90, included reports on the interactions between herbivorous insects and plants exposed to high concentrations of $\mathrm{CO}_{2}$ gas (Agrell et al., 2000; Chen et al., 2005; Dáder et al., 2016). The oviposition behaviour of Cactoblastis cactorum (Stange, 1997, 1999), the feeding behaviour of the larvae of Diabrotica virgifera and Helicoverpa armigera (Rasch and Rembold, 1994; Bernklau and Bjostad, 1998) and the host-searching behaviour of mosquitoes (Gillies, 1980; Eiras and Jepson, 1991), all were reportedly influenced by the concentration of $\mathrm{CO}_{2}$ gas as one of the most important environmental parameters. Most of these studies have been conducted in specialized rooms, especially in greenhouses or closed rooms with specific controlled parameters (Kimball et al., 2002).

In most studies, the $\mathrm{CO}_{2}$ concentration was usually raised to twice the ambient level, or monitored between 700-720 ppm (Hughes and Bazzaz, 2001; Veteli et al., 2002; Johns et al., 2003). Therefore, our objectives were to investigate the effect of increasing $\mathrm{CO}_{2}$ levels on the colour changes, mortality rates, life cycle and life span of the oil palm pest, the nitidulid beetle Carpophilus mutilatus reared under two different conditions, i.e. within the Rearing Room (RR) and in the Open Roof Ventilation Greenhouse System (ORVS). The results are expected to be very useful in predicting the future changes in the population of nitidulid beetles, particularly the pest species of our oil palm crop (Blumberg, 2008; Nor Atikah et al., 2019).

\section{Materials and Methods}

\section{Trap design}

The nitidulid beetle trap in the field was designed using a $1.0 \mathrm{~L}$ transparent plastic container with a cover. A $10.2 \mathrm{~cm} \times 5.1 \mathrm{~cm}$ window was cut $5 \mathrm{~cm}$ from the top edge of the trap and then covered with a muslin cloth for air ventilation. The trap was filled with 
dried soil up to $10 \mathrm{~cm}$ from its base. A rope was fastened to both sides of the trap to hang it onto a palm tree. Ripe bananas were used as food bait (Figure 1).

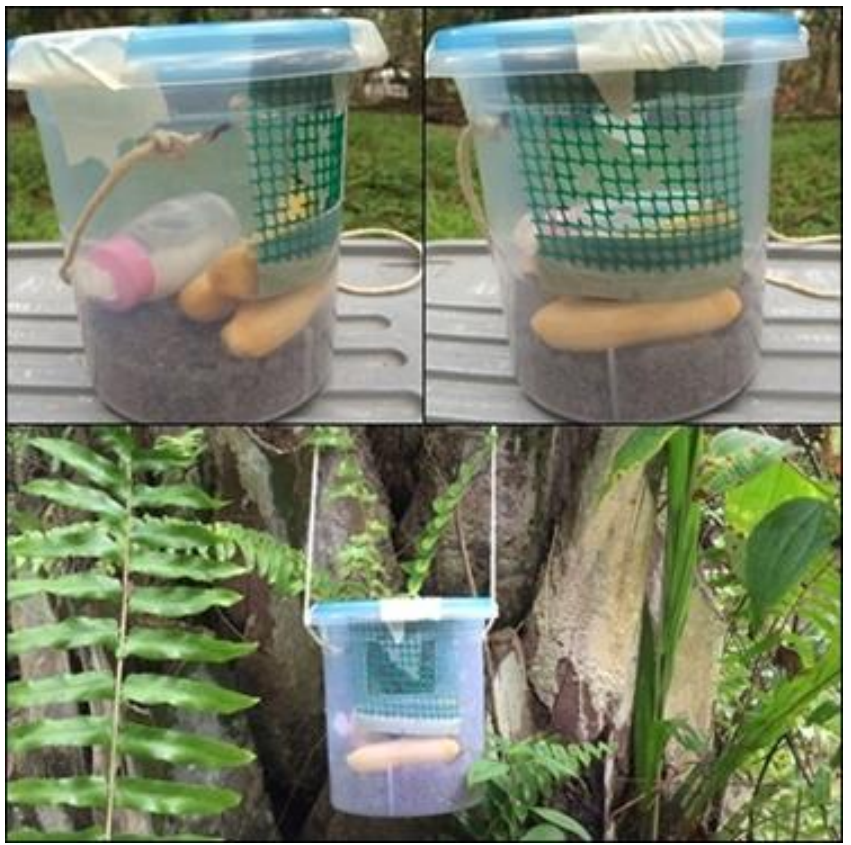

Figure 1. Trap of C. mutilatus

\section{Cultural sampling of C. mutilatus}

The sampling of $C$. mutilatus was conducted in September 2015 at an oil palm plantation in Felda Lui Muda, Negeri Sembilan, in the west coast of Peninsular Malaysia (GPS: latitude 3.013396 longitude 102.379504). The traps were used to obtain live samples of $C$. mutilatus for rearing process in the Rearing Room (RR). In the sampling area, only mature palm trees (aged 18 years and above) were selected for trapping. Three traps were hanged randomly $1 \mathrm{~m}$ above ground at $50 \mathrm{~m}$ apart from each other. The traps were inspected every three days and each trap was placed in a container containing ripe fruits and water. The trapped nitidulid beetles were taken to the Centre for Insect Systematics (CIS) laboratory, Universiti Kebangsaan Malaysia (UKM) for species identification. Only beetles from $C$. mutilatus species were selected for the rearing process in the rearing room.

\section{Rearing process of C. mutilates in the Rearing Room (RR)}

The rearing of $C$. mutilatus was conducted in the Rearing Room at the Biology Building, Faculty of Science and Technology, UKM following the method by Nur Hasyimah et al. (2018). The room temperature and humidity were controlled at $28-32{ }^{\circ} \mathrm{C}$ and $77-85 \%$. A $19 \times 14 \times 12 \mathrm{~cm}$ transparent plastic container was used to rear the C. mutilatus specimen samples. The container was covered using a muslin cloth to prevent the beetles from escaping and a $3 \mathrm{~cm}$ depth of soil medium was placed inside each container to simulate the original natural habitat of $C$. mutilatus and to maintain moisture. In this study, the selected culture room was a closed system that was used exclusively for insect rearing and was also free from chemical contamination and other animals or insects. The room also had a good ventilation system to maintain the 
temperatures at $28-32{ }^{\circ} \mathrm{C}$ and $77-85 \%$ humidity. Controlling temperature and humidity at appropriate levels is important to prevent fungus and other diseases that could affect the rearing process of the beetles (Singh, 1982).

A total of 200 test beetles were used for the experiment with 20 randomly selected individuals of $C$. mutilatus species placed in 10 different containers (replicates). In this study, only 20 adult beetles were placed in each culture container to prevent overpopulation, which could lead to a reduction in survival rates due to injury and lack of phosphorylation. The $3 \mathrm{~cm}$ depth of soil medium in the culture container was important for the pupal stage of the nitidulid beetles, which would also involve the process of fertilizing the soil during the developmental stages of their life cycle (Myers, 2001).

Once the larvae reach their optimum growth, they will excavate up to $2.5-7.5 \mathrm{~cm}$ depth in the soil to provide space for the pupal stage (Capinera, 2001). Water was sprayed every three days to maintain moisture in the container and ripe banana fruit was provided as a food source. The diet or food source provided is an important factor for optimal growth. In this study, mature palm fruit was given to the adult beetles as a food source. Palm fruit also provided a suitable medium for egg-laying and larval growth of the nitidulid beetles. The female would deposit its eggs in the mesocarp and in the early stage of development the larvae would eat and crawl within the fruit before exiting and searching for soil to continue with further pupal development (Glazer et al., 2007). Adult beetles would enter the palm fruit on the calcareous side and obtain food through the fibers (Blumberg, 2008).

The temperature and humidity parameters were monitored every three days using a Digital Hygrometer, i.e. a MEXTECH TM-2 model (Global Instruments, new Delhi, India) while $\mathrm{CO}_{2}$ concentration was monitored using a $\mathrm{CO}_{2}$ Meter, i.e a 8802-EN-00 version (BENETECH, China). The $\mathrm{CO}_{2}$ concentration in the RR was between 300-410 ppm.

\section{Rearing process of C. mutilatus in the Open Roof Ventilation Greenhouse (ORVS)}

The same rearing process as above was used for $C$. mutilatus trial specimens placed in ORVS following the method by Nur Hasyimah et al. (2018). The temperature and humidity of the ORVS were controlled using a computerized system and ranged between $25-45^{\circ} \mathrm{C}$ and $37-87 \%$, respectively. Abiotic parameters such as temperature, air humidity and $\mathrm{CO}_{2}$ concentration were monitored every three days through readings on the system's screen display. In ORVS, the $\mathrm{CO}_{2}$ treatment was given daily from 9-11 am. Pure $\mathrm{CO}_{2}$ spraying was continued for two hours at a concentration of $800-950 \mathrm{ppm}$. After two hours, the $\mathrm{CO}_{2}$ levels inside the ORVS was almost equal to the $\mathrm{CO}_{2}$ levels outside. The gas was supplied through a cylinder connected to the air-conditioning system for open-air chambers and vents. The $\mathrm{CO}_{2}$ concentration was regulated by dilution with air produced by an air blower. $\mathrm{CO}_{2}$ analysers were used to monitor $\mathrm{CO}_{2}$ concentrations and the automatically controlled ORVS systems monitored by the Climate Change Institute (IPI), UKM.

\section{Monitoring the life cycle and life span of $C$. mutilatus}

The life cycle of $C$. mutilatus was monitored daily and the emergence of the first instar larvae was recorded. The larvae were promptly isolated into different containers containing the soil medium as described earlier. Larvae that had turned into pupae were removed from the soil and placed in different containers until they became adult beetles. Observations were conducted throughout the life cycle of the beetle up to the adult stage. The number of individuals at each stage (survival rates), lifespan and body colour changes 
were observed and judiciously recorded. In each stage, five individuals were selected and the colour changes were observed every two days under a microscope.

\section{Data analysis}

Two-ANOVA was used to determine any significant differences and variations between the test individuals observed between RR and in ORVS and in the F1 and F2 generations. The analysis was implemented by using Minitab17.

\section{Results}

\section{Effect of the different $\mathrm{CO}_{2}$ concentrations on the external morphology (body colour) of C. mutilatus in RR and ORVS}

Life cycle was observed starting from the instar larval stage 1. No obvious change in body colour was observed in $C$. mutilatus reared in RR and in ORVS, even at elevated $\mathrm{CO}_{2}$ levels. The short life cycle and morphology of $C$. mutilatus from the larval stage are as follows;

The larvae were milky-white colour on the first day of hatching and would turn into yellow when they reach the active stage and started searching for food (Figures 2a-b), while the pupae were white in the early stage, and would turn into brown upon reaching the final stage, and before emerging as adults (Figures $2 c-d$ ). Adult beetles of this species were dark brown or deep brown in colour (Figures $2 e-f$ ).

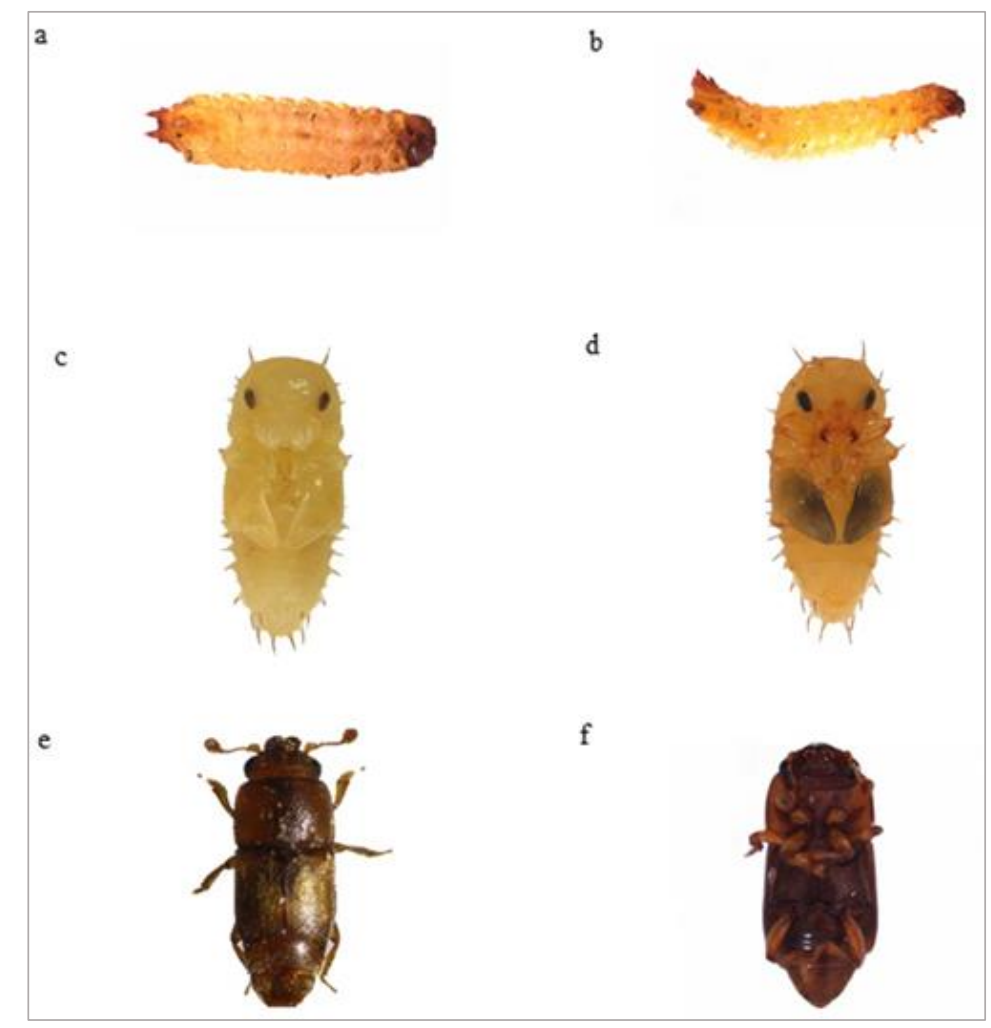

Figure 2. External morphology of C. mutilatus a) Larval stage (ventral) b) Larval stage (c) Early stage d) Pupa stage e) Adult stage (dorsal)f) Adult stage (ventral), taken from the ORVS 


\section{Effect of different $\mathrm{CO}_{2}$ concentrations on the number of individuals, life cycle and life span of C. mutilatus}

The number of live $C$. mutilatus individuals at each developmental stage was recorded in the RR and ORVS systems. The $\mathrm{CO}_{2}$ levels were between 300-410 ppm in the RR, and 800-950 ppm in the ORVS. In the RR, the average live individuals obtained for F1 was 2283 at the larval stage, 1727 at the pupal stage, and 1406 individuals that had successfully emerged into adults. For the F2 generation, from $1406 \mathrm{~F} 1$ adults, 5162 larvae, 4077 pupae and 3771 adults had successfully emerged (Table 1). In the ORVS, the average live individuals obtained for F1 generation was 244 larvae, 99 pupae and 66 adults. As for F2, 66 adults from F1 had produced 34 larvae and 13 pupae, while only one pupa had successfully emerged into the adult stage. In the RR, the species survival rate in the $\mathrm{F} 1$ generation was $61.59 \%$ and had increased to $73.05 \%$ in the $\mathrm{F} 2$ generation. The percentage of species survival rate in ORVS showed a sharp decline from $27.05 \%$ in F1 to $1.5 \%$ in the F2 generation. There was a significant difference in the number of individuals between RR and ORVS in the F1 and F2 generations ( F 12.76, p=0.001, p < 0.05) (Figure 3).

Table 1. Number of C. mutilatus individuals of F1 and F2 in the RR and ORVS systems

\begin{tabular}{c|c|c|c|c|c|c|c}
\hline \multicolumn{2}{c|}{ Generation } & \multicolumn{3}{c|}{ 1st Generation (F1) } & \multicolumn{3}{c}{ 2nd Generation (F2) } \\
\hline Room & CO $_{2}$ levels (ppm) & Larvae & Pupae & Adult & Larvae & Pupae & Adult \\
\hline RR & $300-410 \mathrm{ppm}$ & 2283 & 1727 & 1406 & 5162 & 4077 & 3771 \\
ORVS & $800-950 \mathrm{ppm}$ & 244 & 99 & 66 & 34 & 13 & 1 \\
\hline
\end{tabular}

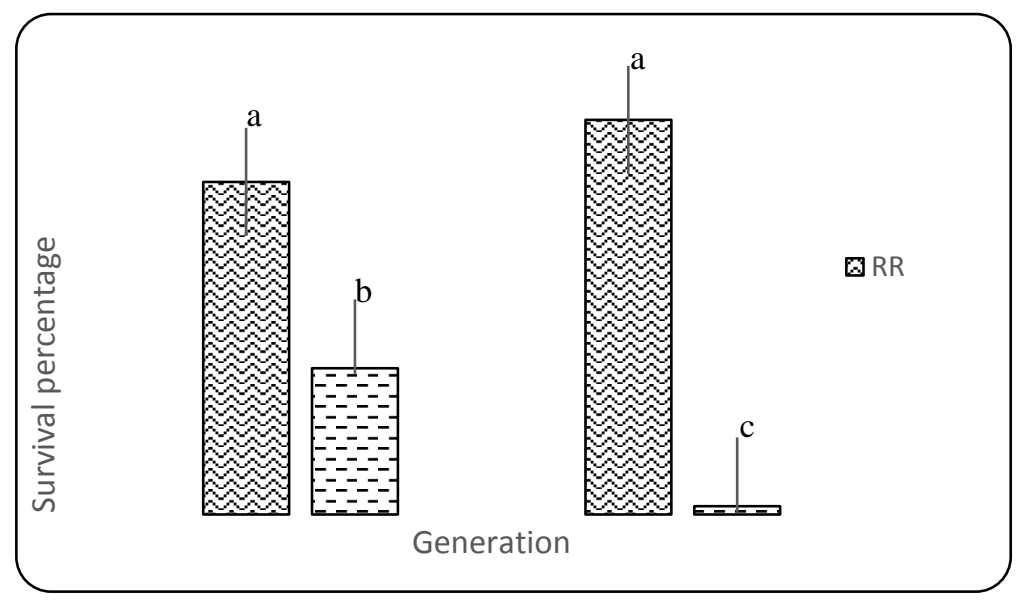

Figure 3. Percentage of C. mutilatus F1 and F2 survival rates in RR and ORVS systems

The life span of $C$. mutilatus F1 and F2 in RR took about 46 days to complete. In the $\mathrm{RR}$, C. mutilatus took 7-21 days from adult to larval stage, 5-15 days from larval to pupal stage, and 3-10 days from pupal to adult stage. However, in ORVS, the F1 took about 30 days to complete its life cycle, i.e. 7-14 days from adult to larva, 5-10 days from larval to pupal stage, and 3-6 days from pupal to adult stage. However, in the F2 generation, C. mutilatus in ORVS had a shorter life cycle of 22 days, i.e. 7-14 days from adult to larval stage, 0-5 days from larval to pupal stage, and 0-3 days from pupal to adult stage (Figure 4). 


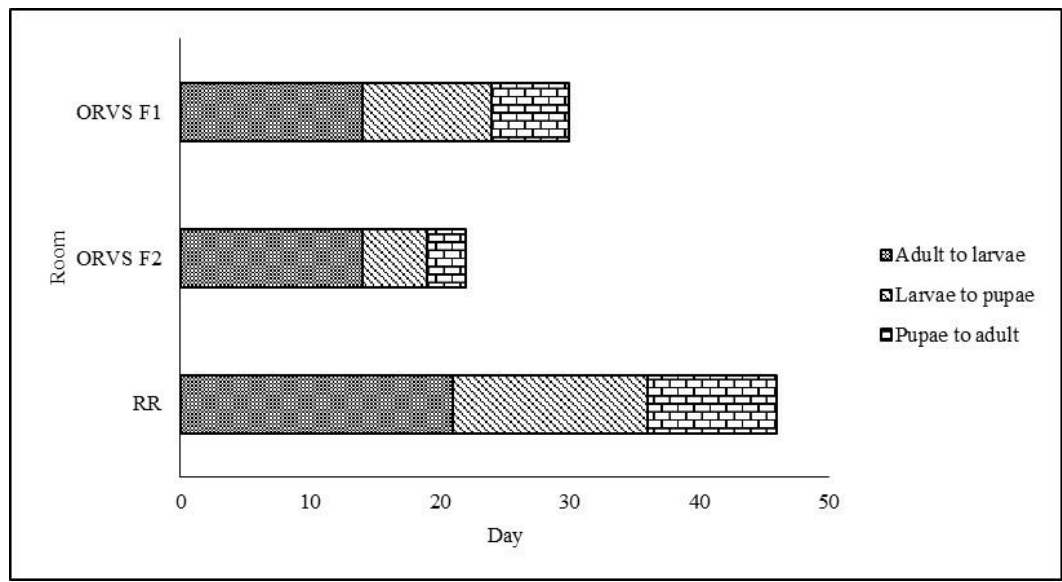

Figure 4. The lifespan of C. mutilatus in RR and ORVS according the developmental stages

According to Table 2, the number of individuals at each life stage in RR and ORVS also significantly differed. In RR, the adult to larva stage showed the highest number of individuals (1549 of F1 and 3147 of F2) compared to ORVS, recorded on day 8-14. In ORVS, the highest number of individuals recorded was 187 of F1 and 30 of F2, on days 0-7. The larval stage in RR was also recorded on days 6-10, with 994 and 2715 individuals of F1 and F2, respectively, while in ORVS the highest number of individuals was recorded on day $0-5$, with 86 of F1 and 13 of F2, respectively. However, the pupal to adult stages in both RR and ORVS systems recorded the highest number of individuals on day 0-3, even though only one individual was recorded in F2 of ORVS.

Table 2. Number of individuals according to the developmental stages of F1 and F2 of C. mutilatus in RR and ORVS systems

\begin{tabular}{c|c|c|c|c|c|c|c|c|c|c}
\hline & & \multicolumn{1}{c}{ Growth development (Days) } \\
\hline \multirow{2}{*}{ Room } & Generation & \multicolumn{3}{|c}{ Adults to larvae } & \multicolumn{3}{c}{ Larvae to pupae } & \multicolumn{3}{c}{ Pupae to adults } \\
\cline { 2 - 11 } & Day & $\mathbf{0 - 7}$ & $\mathbf{8 - 1 4}$ & $\mathbf{1 5 - 2 1}$ & $\mathbf{0 - 5}$ & $\mathbf{6 - 1 0}$ & $\mathbf{1 1 - 1 5}$ & $\mathbf{0 - 3}$ & $\mathbf{4 - 6}$ & $\mathbf{7 - 1 0}$ \\
\hline \multirow{2}{*}{ RR } & F1 & 592 & 1549 & 142 & 556 & 994 & 117 & 992 & 305 & 109 \\
& F2 & 1536 & 3147 & 479 & 1217 & 2715 & 145 & 2774 & 822 & 175 \\
\hline \multirow{2}{*}{ ORVS } & F1 & 187 & 57 & 0 & 86 & 13 & 0 & 61 & 5 & 0 \\
& F2 & 30 & 4 & 0 & 13 & 0 & 0 & 1 & 0 & 0 \\
\hline
\end{tabular}

\section{Discussion}

According to Hunter (2001), the Free-Air Carbon Dioxide Enrichment (FACE) and Open-Top Chamber (OTC), i.e. resembling ORVS, are two effective systems for studying long term interactions of plants and insects. In both systems, the $\mathrm{CO}_{2}$ has been raised abnormally for the purpose of the ecological study, which is believed to have significant influence on the distribution, abundance and performance of insects that feed on plants (herbivorous insects). Furthermore, the elevated levels of $\mathrm{CO}_{2}$ in the atmosphere could exert various effects on many insects either directly or indirectly, leading to marked changes in their life cycle, physiological and behavioural aspects (Lake and Wade, 2009; Yuan et al., 2009). 
From this study, no colour change was detected after exposure of the test beetle individuals to high concentrations of $\mathrm{CO}_{2}$ in the ORVS system. According to Zeuss et al. (2014), colour changes in butterflies would involve a change from lighter to darker coloured in cooler climate, and vice versa at warmer climates when exposed to higher $\mathrm{CO}_{2}$ levels. In our study, despite the different $\mathrm{CO}_{2}$ levels in the culture chambers, no changes were observed based on the morphology (body colour) of each stage of the life cycle. According to Roulin (2014), the increment of $\mathrm{CO}_{2}$ led to a rise in temperature together with the UV radiation. However, the $C$. mutilatus has been categorised as a dark beetle species which is not affected by changes in $\mathrm{CO}_{2}$ levels due to its resistance by the production of melanin. This pigment has become a useful indicator to study the adaptation of insects to climate change. The life cycle of the $C$. mutilatus species occurs mainly inside the ripe oil palm fruit to complete the larval stages before hibernating in the soil during the pupal stage (Nor Atikah et al., 2019).

Furthermore, previous study results indicated that increase in $\mathrm{CO}_{2}$ could also reduce insect abundance by $22 \%$, increase the nutritional rate and life span of certain insects by $17 \%$ and $4 \%$, as well as lowering the growth rate and weight of pupae by $9 \%$ and $5 \%$ (Stiling and Cornelissen, 2007). In our study, significant differences in the number of individuals or abundance in the RR and ORVS systems indicate that high $\mathrm{CO}_{2}$ concentrations could have induced changes in the hatching rate of the nitidulid beetle, C. mutilatus. This is proven by the differences in the survival rates of this species in both culture systems.

The survival rate of $C$. mutilatus in ORVS was lower than in RR, where the rate had also decreased in the F1 and F2 generations. However, the results of this study differ from studies on $C$. dimidiatus by Odeyemi et al. (2004) and C. hemipterus by Gbaye and Odeyemi (2005). Dáder et al. (2016) reported that the aphid, Myzus persicae showed lower survival rates from eggs to adulthood and shorter larval stages in ambient conditions, which was contradictory to our own findings. The egg stage of $C$. dimidiatus showed the highest level of tolerance to high levels of $\mathrm{CO}_{2}$ compared to the other stages in its life cycle. The mortality rate of the eggs was $13.3 \%$ lower than that of the larvae and pupae at $50.0 \%$ and $33.3 \%$, respectively, while $100 \%$ of the adult beetles died after exposure to high $\mathrm{CO}_{2}$ levels for six hours (Odeyemi et al., 2004).

Carpophilus hemipterus also recorded the lowest egg mortality rate of $26.7 \%$ compared to $86.7 \%, 100.0 \%$ and $90.0 \%$ in larval, pupal and adult stages, respectively. However, in our study the egg stage was not successfully obtained from the emerged adults. Most insect eggs require less oxygen to survive compared to the larval, pupal and adult stages. The egg tolerance rate is due to an impermeable layer of egg coral structure that is not present at other stages (Chapman, 1971). In this study, the eggs stages were unsuccessfully collected and thus, not evaluated. However, the percentage of emergence in the pupal and adult stages were higher in larval, continued with pupal and then in adult stages in both conditions and in both generations.

Insects adapt differently when their habitat is changed. At higher $\mathrm{CO}_{2}$ concentrations in ORVS, the life span of $C$. mutilatus was shorter than in the RR. The C. mutilatus F1 and F2 generations also survived, the second generation having a shorter life span than the first generation. The effect of increasing $\mathrm{CO}_{2}$ concentration either in ambient conditions or in the system is usually associated with the interactions of plants and insects. This is because by increasing $\mathrm{CO}_{2}$ the nitrogen cycle is affected and thus, resulting in a decrease in the C:N ratio in the plants (Ainsworth and Long, 2005; Oehme et al., 2013; Ryan et al., 2014). As a result of the changes, macronutrients such as calcium, magnesium 
and phosphorus would decrease due to the lack of water supply from the soil (Taub and Wang, 2008). Therefore, the lack of nutrients and plant quality due to the changes in $\mathrm{CO}_{2}$ concentration would indirectly affect insects through their nutritional responses (Hughes and Bazzaz, 2001; Himanen et al., 2008; Stiling et al., 2013).

Our results showed that the life span of $C$. mutilates was shorter in ORVS compared to the RR, indicating that the life span of the beetles treated with elevated $\mathrm{CO}_{2}$ above the ambient levels had been shortened, and this effect was not limited to F1 but was also observed in the F2 generation. However, this result was contradictory to those of previous studies, which reported that insects tended to reduce their growth rates and extend their life span in order to adapt to high $\mathrm{CO}_{2}$ levels (Goverde and Erhardt, 2003). Insects from Helicoverpa armigera and Orygia leucostigma species also reportedly extended their lifespan when exposed to elevated $\mathrm{CO}_{2}$ levels (Agrell et al., 2000; Chen et al., 2005).

The rise of $\mathrm{CO}_{2}$ levels as a greenhouse gas (GHG) would affect the atmospheric temperature, and both abiotic factors could significantly affect the growth and development of many insect species (Agrell et al., 2000; Goverde and Erhardt, 2003; Mondor and Tremblay, 2010). Although some species are not affected by $\mathrm{CO}_{2}$ changes, but as exothermic organisms, most insects are more sensitive and respond quickly to changes in temperature that affect their life cycles and growth rates (Bale et al., 2002). Insects also respond to rising temperatures by increasing their rates of growth, reproduction and mortality (DeLucia et al., 2012).

The development of nitidulid beetle species, namely $C$. humeralis, $C$. hemipterus and C. mutilatus at different temperatures had been studied by James and Vogele (2000), who reported that the lifespan of these three species were shorter at higher temperatures, i.e. 14-18 days at $32.5{ }^{\circ} \mathrm{C}$ compared to $47-65$ days at $20{ }^{\circ} \mathrm{C}$. These findings, however, contradictory to our results that in RR under ambient conditions $\left(28-32{ }^{\circ} \mathrm{C}\right)$, the total lifespan of $C$. mutilatus was 46 days, whereas for ORVS it was 30 days. The mortality rate for each species was the lowest at temperature between $25-30{ }^{\circ} \mathrm{C}$. The life span of $C$. hemipterus also exhibited similar effects when exposed to different temperature ranges where the growth rates for eggs, larvae and pupae were longer at low temperatures $\left(18{ }^{\circ} \mathrm{C}\right)$ than at high temperatures, $\left(30^{\circ} \mathrm{C}\right)$. However, the mortality rate has increased with increasing temperature (Tsukada et al., 2008). At low temperatures of $-10{ }^{\circ} \mathrm{C}$ to $-8{ }^{\circ} \mathrm{C}$, the mortality rates of $C$. mutilatus and $C$. hemipterus were higher with $100 \%$ mortality (Donahaye et al., 1991).

\section{Conclusion}

The nitidulid beetle $C$. mutilates, was selected as a model species to evaluate the colour changes, survival rate and life span of $C$. mutilatus (Coleoptera: Nitidulidae) in different concentrations of carbon dioxide $\left(\mathrm{CO}_{2}\right)$. This species is interesting because its life cycle from the egg to larval stages is spent inside the oil palm fruit. From this study, no significant changes were observed in the coloration of the larval to adult stages of $C$. mutilatus after exposure to treatment with high ambient $\mathrm{CO}_{2}$ levels. In the $\mathrm{RR}$, the species survival rate in the F1 generation was $61.59 \%$ and had increased up to $73.05 \%$ in the F2 generation. However, the survival rate in ORVS showed a sharp decline from $27.05 \%$ in $\mathrm{F} 1$ to $1.5 \%$ in $\mathrm{F} 2$ generation. Two-ways ANOVA shows there was significant difference in number of individuals between RR and ORVS in F1 and F2 (F 12.76, p=0.001, p < 0.05). The life span of $\mathrm{F} 1$ and $\mathrm{F} 2$ of $C$. mutilatus in RR took about 46 days to complete; i.e. 7-21 days from adult to larval stage, 5-15 days from larval to pupal stage, and 3-10 
days from adult to pupal stage. However, in ORVS, the F1 and F2 generations of $C$. mutilatus took about 30 and 22 days, respectively, to complete their life cycles; i.e. 7-14, 7-14 days from adult to larval stage, 5-10, 0-5 days from larval to pupal stage, and 3-6, 0-3 days from pupal to adult stage, respectively. This data can be used to describe the changes in $C$. mutilatus caused by global warming effects, as $\mathrm{CO}_{2}$ could be one of the main factors affecting the species development. Further ecological study in the field (oil palm plantation) is suggested to relate the growth and development of the nitidulid beetles with other abiotic factors such as temperature, humidity, light intensity and also the most important parameter, i.e. $\mathrm{CO}_{2}$ concentration in order to validate the effects on and biological responses of $C$. mutilatus to climate changes in the natural environment.

Acknowledgements. The authors would like to thank Prof. Dr. Maimon Abdullah for her kind English editing and critical comments on the manuscript. This project was fully supported by the Climate Change Institute (IPI) under the UKM-YSD Chair in Climate Change Grant (ZF-2019-005).

\section{REFERENCES}

[1] Agrell, J., McDonald, E. P., Lindroth, R. L. (2000): Effects of $\mathrm{CO}_{2}$ and light on tree phytochemistry and insect performance. - Oikos 88(2): 259-272.

[2] Ainsworth, E. A., Long, S. P. (2005): What have we learned from 15 years of free-air $\mathrm{CO}_{2}$ enrichment (FACE)? A meta-analytic review of the responses of photosynthesis, canopy properties and plant production to rising $\mathrm{CO}_{2}$. - New Phytologist 165: 351-372.

[3] Bale, J. S., Masters, G. J., Hodkinson, I. D., Awmack, C., Bezemer, T. M., Brown, V. K., Butterfield, J., Buse, A., Coulson, J. C., Farrar, J., Good, J. E. (2002): Herbivory in global climate change research: direct effects of rising temperature on insect herbivores. - Global Change Biology 8(1): 1-16.

[4] Bernklau, E. J., Bjostad, L. B. (1998): Reinvestigation of host location by western corn rootworm larvae (Coleoptera: Chrysomelidae): $\mathrm{CO}_{2}$ is the only volatile attractant. - Journal of Economic Entomology 91: 1331-40.

[5] Blumberg, D. (2008): Review: Date palm arthropod pests and their management in Israel. - Phytoparasitica 36: 411-448.

[6] Capinera, J. L. (2001): Handbook of Vegetable Pests. - Elsevier.

[7] Chapman, R. F. (1971): The Insects: Structure and Function. $-2^{\text {nd }}$ edition, London: Hodder and Stoughton Ltd.

[8] Chen, F., Wu, G., Ge, F., Parajulee, M. N., Shrestha, R. B. (2005): Effects of elevated $\mathrm{CO}_{2}$ and transgenic Bt cotton on plant chemistry, performance, and feeding of an insect herbivore, the cotton bollworm. - Entomologia Experimentalis et Applicata 115(2): 341350 .

[9] Chen, I-C., Shiu, H-J., Benedick, S., Holloway, J. D., Chey, V. K., Barlow, H. S., Hill, J. K., Thomas, C. D. (2009): Elevation increases in moth assemblages over 42 years on a tropical mountain. - Proceedings of the National Academy of Sciences of the United States of America 106: 1479-1483.

[10] Cohen, A. C. (2018): Ecology of Insect Rearing Systems: A Mini-Review of Insect Rearing Papers from 1906-2017. - Advances in Entomology 6(02): 86.

[11] Cox, P. M., Betts, R. A., Jones, C. D., Spall, S. A., Totterdell, I. J. (2000): Acceleration of global warming due to carbon-cycle feedbacks in a coupled climate model. - Nature 408(6809): 184-187.

[12] Cuthbertson, A. G., Mathers, J. J., Blackburn, L. F., Wakefield, M. E., Collins, L. E., Luo, W., Brown, M. A. (2008): Maintaining Aethina tumida (Coleoptera: Nitidulidae) under 
quarantine laboratory conditions in the UK and preliminary observations on its behaviour. - Journal of Apicultural Research 47(3): 192-193.

[13] Dáder, B., Fereres, A., Moreno, A., Trębicki, P. (2016): Elevated $\mathrm{CO}_{2}$ impacts bell pepper growth with consequences to Myzus persicae life history, feeding behaviour and virus transmission ability. - Scientific reports 6: 19120.

[14] De Guzman, L. I., Frake, A. M. (2007): Temperature affects Aethina tumida (Coleoptera: Nitidulidae) development. - Journal of Apicultural Research 46(2): 88-93.

[15] DeLucia, E. H., Nabity, P. D., Zavala, J. A., Berenbaum, M. R. (2012): Climate change: resetting plant-insect interactions. - Plant Physiology 160(4): 1677-1685.

[16] Donahaye, E., Navarro, S., Rindner, M. (1991): The influence of low temperatures on two species of Carpophilus (Col., Nitidulidae). - Journal of Applied Entomology 111(1-5): 297-302.

[17] Dowd, P. F. (1987): A labor saving method for rearing the dried fruit beetle (Coleoptera: Nitidulidae) on pinto bean-based diet. - Journal of Economic Entomology 80(6): 13511353.

[18] Dowd, P. F., Weber, C. M. (1991): A labor-saving method for rearing a corn sap beetle, Carpophilus freeman Dobson (Coleoptera: Nitidulidae), on pinto bean-based diet. Journal of Agricultural Entomology 8(3): 149-153.

[19] Echegaray, E. R., Cloyd, R. A. (2013): Life history characteristics of the rove beetle, Dalotia coriaria (Coleoptera: Staphylinidae) under laboratory conditions. - Journal of the Kansas Entomological Society 86(2): 145-155.

[20] Eiras, A. E., Jepson, P. C. (1991): Host location by Aedes aegypti (Diptera, Culicidae): a wind tunnel study of chemical cues. - Bulletin of Entomological Research 81: 151-60.

[21] EPA, U.S. (2017): Inventory of US greenhouse gas emissions and sinks.

[22] Gbaye, O. A., Odeyemi, O. (2005): Evaluation of hypercarbia atmosphere on the mortality of dried-fruit beetle, Carpophilus hemipterus (Linnaeus). - Journal of Food, Agriculture \& Environment 3(3-4): 43-46.

[23] Gibbs, M., van Dyck, H., Karlsson, B. (2010): Reproductive plasticity, ovarian dynamics and maternal effects in response to temperature and flight in Pararge aegeria. - Journal of Insect Physiology 56(9): 1275-1283.

[24] Gillies, M. T. (1980): The role of carbon dioxide in host-finding by mosquitoes (Diptera: Culicidae): a review. - Bulletin of Entomological Research 70(4): 525-532.

[25] Glazer, I., Eliyau, M., Salame, L., Nakash, Y., Blumberg, D. (2007): Evaluation of the efficacy of the entomopathogenic nematodes Heterorhabditis sp. against sap beetles (Coleoptera: Nitidulidae). - Biocontrol 52(2): 259-270.

[26] Goverde, M., Erhardt, A. (2003): Effects of elevated $\mathrm{CO}_{2}$ on development and larval food preference in the butterfly Coenonympha pamphius (Lepidoptera, Satyridae). - Global Change Biology 9: 74-83.

[27] Gurr, G. M., Barlow, N. D., Memmott, J., Wratten, S. D., Greathead, J. (2000): A history of methodological, theoretical and empirical approaches to biological control. Biological Control: Measures of Success. - Dordrecht, The Netherlands: Kluwer Academic Publishers.

[28] Himanen, S. J., Nissinen, A., Dong, W. X., Nerg, A. M., Stewart Jr, C. N., Poppy, G. M., Holopainen, J. K. (2008): Interactions of elevated carbon dioxide and temperature with aphid feeding on transgenic oilseed rape: Are Bacillus thuringiensis (Bt) plants more susceptible to non target herbivores in future climate? - Global Change Biology 14: 1-18.

[29] Hughes, L., Bazzaz, F. A. (2001): Effects of elevated $\mathrm{CO}_{2}$ on five plant-aphid interactions. - Entomologia Experimentalis et Applicata 99: 87-96.

[30] Hunter, M. D. (2001): Effects of elevated atmospheric carbon dioxide on insect-plant interactions. - Agricultural and Forest Entomology 3(3): 153-159.

[31] James, D. G., Vogele, B. (2000): Development and survivorship of Carpophilus hemipterus (L.), Carpophilus mutilatus Erichson and Carpophilus humeralis (F.) (Coleoptera: 
Nitidulidae) over a range of constant temperatures. - Australian Journal of Entomology 39(3): 180-184.

[32] Johns, C. V., Beaumont, L. J., Hughes, L. (2003): Effects of elevated $\mathrm{CO}_{2}$ and temperature on development and consumption rates of Octotoma championi and O. scabripennis feeding on Lantana camara. - Entomologia Experimentalis et Applicata 108(3): 169-178.

[33] Khaliq, A., Javed, M., Sohail, M., Sagheer, M. (2014): Environmental effects on insects and their population dynamics. - Journal of Entomology and Zoology Studies 2(2): 1-7.

[34] Kimball, B. A., Kobayashi, K., Bindi, M. (2002): Responses of agricultural crops to freeair $\mathrm{CO}_{2}$ enrichment. - Advances in Agronomy 77: 293-368.

[35] Lake, J. A., Wade, N. (2009): Plant-pathogen interactions and elevated $\mathrm{CO}_{2}$ : morphological changes in favour of pathogens. - Journal of Experimental Botany 60: 3123-3131.

[36] Leppla, N. C. (2009): Rearing of Insects. - Encyclopedia of Insects, pp. 866-869.

[37] Meikle, W. G., Patt, J. M. (2011): The effects of temperature, diet, and other factors on development, survivorship, and oviposition of Aethina tumida (Coleoptera: Nitidulidae). Journal of Economic Entomology 104(3): 753-763.

[38] Meinshausen, M., Meinshausen, N., Hare, W., Raper, S. C., Frieler, K., Knutti, R., Frame, D. J., Allen, M. R. (2009): Greenhouse-gas emission targets for limiting global warming to $2^{\circ}$ C. - Nature 458(7242): 1158.

[39] Mondor, E., Tremblay, M. (2010): Global Atmospheric Change and Animal Populations. - Nature Education Knowledge 3(10): 23.

[40] Myers, L. (2001): Sap Beetles in Florida. University of Florida, Department of Entomology and Nematology. - Featured Creatures. EENY-256.

[41] Nor Atikah, A. R., Halim, M., Syarifah Zulaikha, S. A., Yaakop, S. (2019): Molecular identification and first documentation of seven species of Carpophilus Stephens (Nitidulidae: Carpophilinae) in oil palm ecosystem, Peninsular Malaysia. - Journal of AsiaPacific Entomology 22(2): 619-624.

[42] Nur Hasyimah, R., Nor Atikah, A. R., Halim, M., Muhaimin, A. M. D., Nizam, M. S., Hanafiah, M. M., Yaakop, S. (2018): $\mathrm{CO}_{2}$ effects on larval development and genetics of mealworm beetle, Tenebrio molitor L. (Coleoptera: Tenebrionidae) in two different $\mathrm{CO}_{2}$ systems. - Applied Ecology and Environmental Research 16(2): 1749-1766.

[43] Odeyemi, O., Gbaye, O., Aborisade, A. (2004): Mortality of life stages of Carpophilus dimidiatus (F) exposed to carbon dioxide Atmosphere. - Proceedings of International Conference on Controlled Atmosphere and Fumigation in Stored Products, pp. 89-98.

[44] Oehme, V., Högy, P., Zebitz, C. P. W., Fangmeier, A. (2013): Effects of elevated atmospheric $\mathrm{CO}_{2}$ concentrations on phloem sap composition of spring crops and aphid performance. - Journal of Plant Interactions 8: 74-84.

[45] Okada, K., Miyatake, T. (2007): Librodor japonicas (Coleoptera: Nitidulidae): life history, effect of temperature on development, and seasonal abundance. - Applied Entomology and Zoology 42(3): 411-417.

[46] Peng, C., Williams, R. N. (1990): Artificial diet for the strawberry sap beetle, Stelidota geminate (Say) (Coleoptera: Nitidulidae). - Journal of Agricultural Entomology 7(2): 137140.

[47] Peñuelas, J., Filella, I., Comas, P. (2002): Changed plant and animal life cycles from 1952 to 2000 in the Mediterranean region. - Global Change Biology 8(6): 531-544.

[48] Rasch, C., Rembold, H. (1994): Carbon dioxide: highly attractive signal for larvae of Helicoverpa armigera. - Naturwissenschaften 81: 228-29.

[49] Root, T. L., Price, J. T., Hall, K. R., Schneider, S. H., Rosenzweig, C., Pounds, J. A. (2003): Fingerprints of global warming on wild animals and plants. - Nature 421(6918): 57.

[50] Roy, D. B., Sparks, T. H. (2000): Phenology of British butterflies and climate change. Global Change Biology 6(4): 407-416.

[51] Ryan, G. D., Rasmussen, S., Xue, H., Parsons, A. J., Newman, J. A. (2014): Metabolite analysis of the effects of elevated $\mathrm{CO}_{2}$ and nitrogen fertilization on the association between 
tall fescue (Schedonorus arundinaceus) and its fungal symbiont Neotyphodium coenophialum. - Plant, Cell and Environment 37: 204-212.

[52] Singh, P. (1982): The rearing of beneficial insects. - New Zealand Entomologist 7(3): 304310 .

[53] Stange, G. (1997): Effects of changes in atmospheric carbon dioxide on the location of hosts by the moth, Cactoblastis cactorum. - Oecologia 110: 539-45.

[54] Stange, G. (1999): Carbon dioxide is a close-range oviposition attractant in the Queensland fruit fly Bactrocera tryoni. - Naturwissenschaften 86: 190-92.

[55] Stiling, P., Cornelissen, T. (2007): How does elevated carbon dioxide $\left(\mathrm{CO}_{2}\right)$ affect plant herbivore interactions? A field experiment and a meta-analysis of $\mathrm{CO}_{2}$-mediated changes on plant chemistry and herbivore performance. - Global Change Biology 13: 1823-1842.

[56] Stiling, P., Moon, D., Rossi, A., Forkner, R., Hungate, B. A., Day, F. P., Schroeder, R. E., Drake, B. (2013): Direct and legacy effects of long-term elevated $\mathrm{CO}_{2}$ on fine root growth and plant-insect interactions. - New Phytologist 200(3): 788-795.

[57] Taub, D. R., Wang, X. Z. (2008): Why are nitrogen concentrations in plant tissues lower under elevated $\mathrm{CO}_{2}$ ? A critical examination of the hypotheses. - Journal of Integrative Plant Biology 50: 1365-1374.

[58] Tsukada, M., Asai, M., Higuchi, H. (2005): Developmental period and adult size of Haptoncus ocularis (Coleoptera: Nitidulidae) at four temperature conditions. - Applied Entomology and Zoology 40(3): 489-495.

[59] Tsukada, M., Tanaka, D., Higuchi, H. (2008): Thermal requirement for development of Carpophilus marginellus (Coleoptera: Nitidulidae), a potential pollinator of cherimoya and atemoya trees (Magnoliales: Annonaceae). - Applied Entomology and Zoology 43(2): 281285.

[60] Veteli, T. O., Kuokkanen, K., Julkunen-Tiitto, R., Roininen, H., Tahvanainen, J. (2002): Effects of elevated $\mathrm{CO}_{2}$ and temperature on plant growth and herbivore defensive chemistry. - Global Change Biology 8(12): 1240-1252.

[61] Wallis de Vries, M. F., Van Swaay, C. A. M. (2006): Global warming and excess nitrogen may induce butterfly decline by microclimatic cooling. - Global Change Biology 12: 16201626.

[62] Yuan, J. S., Himanen, S. J., Holopainen, J. K., Chen, F., Stewart, C. N. (2009): Smelling global climate change: mitigation of function for plant volatile organic compounds. Trends in Ecology and Evolution 24: 323-331.

[63] Zeuss, D., Brandl, R., Brändle, M., Rahbek, C., Brunzel, S. (2014): Global warming favours light-coloured insects in Europe. - Nature Communications 5: 3874. 